\title{
Performing Argumentative Writing in English: Difficulties, Processes, and Strategies
}

Wei Zhu

Argumentative writing constitutes an important part of second-language learners' academic writing experience in North America. This study examined the difficulties a group of Mexican graduate students encountered when engaged in an argumentative writing task as well as their writing processes and strategies. Data were collected from individual interviews with the participants and from participants' written essays. Data analysis indicated that most participants perceived the rhetorical aspects of English argumentative writing as difficult. Data analysis also indicated that participants mainly used cognitive, social, and search strategies, whereas metacognitive strategies were used infrequently. Potential implications of the study for second-language writing instruction are discussed.

En Amérique du Nord, la rédaction de textes argumentatifs est une partie importante de l'expérience académique d'apprenants en ALS. Cet article étudie les difficultés auxquelles des étudiants mexicains gradués se sont heurtés dans la rédaction de textes argumentatifs, et évoque les processus et stratégies auxquels ils ont recours. Des données ont été recueillies à partir d'entrevues individuelles auprès des participants et de leurs rédactions. Une analyse des données a révélé que la plupart des participants perçoivent que les éléments rhétoriques causent des difficultés dans la rédaction de textes argumentatifs en anglais. Il est également sorti de l'analyse que les participants avaient surtout recours à des stratégies cognitives, sociales et de recherche, plutôt qu'à des stratégies métacognitives. L'auteur présente des implications découlant de cette étude qui pourraient s'appliquer à l'enseignement de la rédaction en langue seconde.

\section{Introduction}

Argumentative writing as a mode of academic writing constitutes an important part of second-language learners' academic experience at the college level in North America. Depending on their fields of study, second-language writers may be asked to support a managerial decision, argue for an international policy, or evaluate a model developed to solve a particular problem. Because of the prevalence of argumentative writing in the academic curriculum, and because of the challenges associated with its development, a 
common component of English as a second language (ESL) writing classes consists of helping second-language learners develop argumentative writing skills.

Second-language writing research has examined both L2 argumentative texts and the processes and strategies used in producing argumentative writing in a second language. Text-based research has indicated that English argumentative writing poses rhetorical difficulties for second-language writers. For example, Al-Abed-Al-Haq and Ahmed (1994) examined 62 argumentative essays written in English by Saudi university students learning English as a second language. By evaluating nine components and 24 subcomponents of the argumentative essays, Al-Abed-Al-Haq and Ahmed found that quantity (completeness and balance in arguments and counterarguments), argumentativeness (development, support, organization, and persuasiveness of the argument), and thesis (clarity and qualification of the thesis and the direction the thesis provides for the reader) were the most difficult areas for the Saudi students. Text-based research that has compared argumentative writing by native and nonnative English speakers reveals rhetorical and textual differences, although some similarities have also been found (Bouchard, 1996; Choi, 1986, 1988a, 1988b; Ferris, 1994; Hinkel, 1999; Kim, 1996; Lux, 1991). For example, Ferris (1994) and Hinkel (1999) found that native English speakers and ESL students differed with respect to how they handled counterarguments. Lux (1991) found that compared with L1 English-speaking college students, native Spanish-speaking students favored an elaborate style in writing on an argumentative task. To some extent, these differences reflect the difficulties facing L2 writers when they deal with the rhetorical aspects of English argumentative writing.

Many of the rhetorical difficulties and differences observed through textual analysis of L2 argumentative essays were explained in terms of the transfer of the cultural and linguistic influences from the writer's first language. However, the "newly defined contrastive rhetoric" (Connor, 1996) sees that L2 texts and writing are influenced by an array of factors. Researchers interested in the application of contrastive rhetoric research in second-language writing instruction have argued for the importance of going beyond cultural and linguistic factors as sole explanations for textual features observed in L2 writing. For example, Matsuda (1997) argues that the writer's cultural and linguistic background, though still relevant, should no longer be seen as the only explanation for organizational features in L2 texts.

Second-language writing research has also examined the processes and strategies L2 writers employ to accomplish argumentative writing tasks. Several studies undertaken in the late 1980s and early 1990s to examine student writing processes included an argumentative task (Cumming, 1989; Hall; 1990; Raimes, 1987; Whalen \& Menard, 1995). For example, Raimes (1987) examined the strategies employed by two groups of ESL students 
(remedial and nonremedial) as they were performing two tasks: a descriptive task and an argumentative task. The strategies Raimes focused on were planning, rehearsing, rescanning, rereading the topic, revising, and editing. More recent research examining L2 writing processes and strategies has broadened the scope of investigation and provided comprehensive frameworks for classifying writing strategies (Khaldieh, 2000; Leki, 1995; Riazi, 1997), although not all research has specifically focused on argumentative tasks. For example, in his study of four Iranian doctoral students learning to write in the field of education, Riazi (1997) classified the strategies used by his participants into four categories: cognitive, metacognitive, social, and search. According to Riazi, cognitive strategies are responsible for "interacting with the materials to be used in writing by manipulating them mentally or physically" (p. 122). Metacognitive strategies are those "executive processes used to plan, monitor, and evaluate a writing task" (p. 122), and social strategies allow "interacting with other persons to assist in performing the task or to gain affective control" (p. 122). The search strategies involve searching and using supporting sources such as looking for models. Khaldieh's (2000) research indicates that affective strategies are also important. Khaldieh examined the strategies used by 43 American learners of Arabic on two argumentative tasks and found that a big difference between the proficient versus less proficient learners concerned the affective domain. Khaldieh argues for the inclusion of affective strategies in writing strategy training.

Thus, as shown above, L2 writers' difficulties with English argumentative writing have largely been approached from the textual perspective (what the researchers or readers can detect from the written products). Few studies, however, have examined learners' difficulties from the learner's perspective by eliciting input from the L2 writers (what the L2 writers perceive to be difficult). Yet an understanding of writing difficulties and needs from the writer's point of view is important because it can help teachers provide meaningful and relevant instruction by adopting teaching strategies that address the specific difficulties and needs of L2 learners. Leki and Carson (1994) believe it is important to understand students' needs by asking students what difficulties they experience. They argue that "this type of needs assessment is appropriate for all students in any environment" (p. 95), although their study focused specifically on ESL students transitioning into university-content courses from EAP courses. As for writing processes and strategies, existing studies on argumentative writing have focused on processes and strategies associated with timed essays with given topics. Timed tasks with given topics, however, represent only one type of task required of students in ESL writing or content courses. The processes and strategies L2 writers use to tackle out-of-class argumentative tasks remain to be better understood. 
The study reported below aimed at extending research on L2 argumentative writing by (a) examining L2 writers' difficulties in learning to perform English argumentative writing from the L2 writers' perspective, and (b) examining the processes and strategies L2 writers use to accomplish an out-of-class argumentative writing assignment. The research is holistic in nature (Seliger \& Shohamy, 1989) and adopts a qualitative approach. The specific research questions are:

1. From the L2 writers' perspective, what are their difficulties when they perform an argumentative writing task in English?

2. What processes and strategies do L2 writers use when they perform an argumentative writing task in English?

\section{Methodology}

\section{Participants}

Information about the participants was collected through the individual interviews described below. Participants in this study were $14^{1}$ Mexican graduate students who had been admitted into an MA program in teaching English as a second language offered at a US University. All 14, 5 male and 9 female, were English teachers in Mexico, with years of English teaching experience at the college level ranging from 2.5 to 17 years. Some had also taught at other levels. All spoke Spanish as their first language, except for one who was born in the US and learned English as her first language. This individual, however, moved to Mexico when she was 6 and said that Spanish became her dominant language. Participants' TOEFL scores ranged from about 500 to 650 . All had earned bachelor's degrees in various fields, and several had earned master's degrees in education in Mexico. One had a doctoral degree in biochemistry from a French university. Several participants said that they had little experience writing essays in their native language. As for writing experience in English, nine participants indicated that the argumentative assignment discussed below was the first essay they ever had to write in English. Although the other five had written English essays before, they indicated that their experience with argumentative writing in English was limited. All participants, however, had completed a couple of assignments such as lesson plans in English in a grammar course taken previously.

\section{Context}

This study took place in the summer of 1998 in a five-week course in which the 14 participants were enrolled. The course covered basic concepts in linguistics for the first half of the semester and writing development and instruction for the second half. Not a composition class per se, the course was designed for education majors and was considered a good preparation 
course for the Mexican students. The class met for about two hours every day for five full weeks, and the participants took the course with approximately 20 American undergraduate students. For the writing component of the course, one of the requirements was a two-page argumentative essay. ${ }^{2}$ In the class session in which the essay was assigned, I reviewed and presented the argumentative essay as "a paper grounded on logical, structured evidence that attempts to convince the reader to accept an opinion, take some action, or do both" (Reinking, Hart, \& Osten, 1993, p. 140). We spent about 30 minutes discussing how to convince readers by supporting the arguments using different types of evidence (e.g., facts, opinions of authority, personal experience). We also discussed how an argumentative essay might be organized. Students were asked to select their own topics and were given a week to complete the assignment outside of class. Students were encouraged to start writing as soon as possible and to revise their drafts, although no drafts were required to be submitted. ${ }^{3}$

\section{Data Analysis}

The major source of data collected and analyzed came from individual interviews of the participants. Participants' essays constituted an additional source of data. The semi-structured interviews (Seliger \& Shohamy, 1989) took place shortly after participants completed the assignment and ranged from approximately 60 to 90 minutes (see Appendix for the interview protocol). I took notes during the interviews, but also tape-recorded all the interviews with the participants' permission. The interviews elicited information about participants' backgrounds and oral reports concerning participants' difficulties, processes, and strategies when performing the argumentative writing task. Although oral reports after the fact, referred to as "self-observations" (Wallace, 1998), have certain limitations (e.g., participants may not be able to recall certain events), they do not interrupt normal composing processes and seemed most suitable for a study involving an out-of-class assignment. Most participants in this study did not seem to have difficulties recalling specific information on the argumentative assignment when prompted.

Data analysis took several steps. First, I listened to all the tapes to check the accuracy of my notes. Responses to the open-ended questions concerning difficulties, processes, and strategies were transcribed, resulting in 119 pages of transcripts. One interview (with Monica) was not properly recorded and therefore was reconstructed based on my notes. I assigned each participant a pseudonym based on a list of Spanish names provided by a native Spanish speaker. Responses were grouped according to the interview questions, and those responses that contained similar themes were grouped together. Thus the approach taken to analyze responses to the open-ended questions was inductive. Because the goal was to examine the specific difficulties par- 
ticipants experienced and the specific processes and strategies used, related categories were not combined. For example, with respect to difficulties experienced during writing, some participants mentioned that they found conclusions difficult to write and that they had difficulties with the structure of argumentative writing. Although conclusion is a component of the structure and could have been subsumed under the category structure of writing, the two categories were kept apart.

\section{Results}

Question 1. From the L2 writers' perspective, what are their difficulties when they perform an argumentative writing task in English?

The 14 participants were asked what difficulties they encountered while working on the argumentative assignment. Most participants perceived the argumentative assignment as a challenging and even stressful task. Several indicated that the anxiety level was high when they were working on the assignment. They used phrases such as "really stressful" to describe the task. One participant, Sonia, said that it was so stressful that she almost gave up the assignment. She said,

I was so desperate ... and then I was thinking "should I keep on doing it or should I study for the exam?" ... At one moment I was real desperate. You know, I thought I won't do it. And then I changed my mind. I think I have to do it. At least, I have to try. (Sonia's transcript, pp. 6-7)

Table 1 summarizes the specific difficulties that were reported by at least two participants. As shown in the table, more than half of the participants reported having difficulty with the form, the structure/organization, of argumentative writing. "It was the organization of ideas" was a frequent response when participants were asked what they found challenging while writing the essay. Participants said that they were not sure about the structure of their essays (the components) and found it difficult to organize ideas. Comments from a few participants suggested that lack of knowledge of the rhetorical structure of English argumentative writing was a major source of the anxiety they experienced as reflected in this comment: "Because you know you are not so sure about if that was the correct form. You are still afraid of doing the wrong thing" (Teresa's transcript, p. 9).

In addition to structure/organization, half of the participants said that they found the page limit to be a difficulty because they had more to say than what was required ( 2 pages). As a result, they were "really really concerned about the limit" (Teresa's transcript, p. 11). A careful reading of participants' comments suggested that participants' difficulty in conforming to the page limit partly reflected their difficulty in developing the argument (selecting an appropriate number of ideas and details for inclusion) and in achieving 
Table 1

Difficulties Reported by the Participants $(N=14)$

$\begin{array}{ll}\text { Structure/Organization } & 8 \\ \text { Page Limit } & 7 \\ \text { Punctuation } & 4 \\ \text { Conclusion/Closure } & 4 \\ \text { Vocabulary } & 3 \\ \text { Topic Selection } & 2 \\ \text { Grammar } & 2\end{array}$

economy in expression (to be direct). For example, Dora said that she found it challenging to balance the content "with the length or maybe with the details" (Dora's transcript, p. 3). A few participants said that they were used to writing many words and that in their native language a more embellished style would be more appropriate. Comments from a couple of participants also indicated that the page limit was another trigger of anxiety and perhaps an additional cognitive burden as well, because, as Adriana felt, participants had to keep the limit in mind while writing and worry about possibly losing points.

Other difficulties participants reported included punctuation, conclusion, vocabulary, topic selection, and grammar. Four participants said that they did not know the punctuation rules in English, and four said conclusions were difficult to write because they did not know what to include. Three participants said that they had difficulty with vocabulary, and two of the three said it was lack of vocabulary appropriate for formal writing (vs. general vocabulary) that caused the problem. This was evident in Juanita's comment, "I don't have a lot of vocabulary. I mean a lot of vocabulary for formal writing, for academic writing" (Juanita's transcript, p. 11). Rafael's comment further clarified this; he said, "You argue with different words, and we don't know many of the words you can use argumentative[ly] here" (Rafael's transcript, p. 3). When asked what some of those words would be, Rafael's examples indicated that he was thinking about expressions often used in academic writing, for example, logical connectors. He said "For example, 'This can be done but ...' Maybe there are many more words we can use instead of 'but.' I don't have the expressions to say something argumentative. The words you can argue with" (Rafael's transcript, p. 4)

Participants' comments concerning their difficulties indicated that from the L2 writers' perspective, cultural and language backgrounds were among, but did not constitute all the factors that could account for their difficulties (or lack of difficulties). Perhaps because of their training, most participants in this study were well aware of the potential influences of culture on writing, as well as the rhetorical differences between Spanish and English writing, 
and several participants offered language and cultural differences as explanations for their difficulties. For example, Sonia, who reported difficulty with organization, said, "Well, you have known this already, I have trouble with organization. Here it is not the same [as] in Mexico" (Sonia's transcript, p. 7). Pedro, commenting on the differences concerning directness in Spanish and English, said, "Well, in Spanish, it's like we like to have long introduction, and probably, two or three paragraphs later, then we go to the topic, that's what I can say [is] different" (Pedro's transcript, p. 1). Other participants, however, cited other factors. Juanita, who reported having difficulty organizing ideas for the argumentative essay, said that she had similar difficulties when writing in Spanish. Several participants attributed their difficulties to their lack of experience with academic writing in English or Spanish. Two participants suggested their training in specific fields as potential influences on their writing. For example, David, who had earned a doctorate in biochemistry, said that because most scientists were trained to be direct in their writing, he did not find it difficult to be direct in his essay.

In order to see whether students' perceived difficulties were evident in the written products, I read participants' essays, noting the main strengths and weaknesses in each essay and then compared the weaknesses noted for each essay with the difficulties reported by each writer. Interestingly, this comparison revealed no complete match between self-reported difficulties and weaknesses observed by examining the finished written products. Some of the reported difficulties were either not evident in the essays or did not constitute the major weaknesses as observed in the essays; conversely, some of the major weaknesses observed were not perceived and reported by the participants as difficulties. For example, eight participants reported having difficulty with the structure of the essay, and yet five of the essays did not exhibit major problems with the structure (thesis + arguments/counterarguments + support + conclusion). None of the participants who reported having difficulty with the conclusion omitted or wrote grossly ineffective conclusions. For example, Mario perceived conclusion to be a major difficulty, yet in his essay, which argued the need for a syllabus for English classes in Mexico, he wrote the conclusion shown below. Although the conclusion was not perfect, it served the purpose of bringing closure to the essay by summarizing the major advantages of having a syllabus.

I will conclude this report by saying that it is important for teachers to write a syllabus before the semester begins so that they are prepared for the semester. Of course, if teachers spend more time and energy on writing the syllabus, this would cause the authorities to increase the teachers budget. Another thing is that students would benefit from this as well in aspects such as knowing the contents and objectives of the course, dates of evaluations among others. In a few words, our institu- 
tion would provide students with a valuable tool that will help them achieve their objectives.

In contrast, weaknesses were observed in some areas in which participants did not perceive and report difficulties. For example, several essays were weak in paragraph development and use of transitions, yet the authors did not mention difficulties in these areas. Also, the written products showed that several writers represented the assignment as an expository rather than argumentative task, yet the writers did not report having difficulty understanding the assignment and representing the task.

Thus comparing self-reported difficulties with observed weaknesses revealed a gap between the two. Although several factors related to writers' perceptions (such as the writers' knowledge of and ability to evaluate writing) and my own subjectivity in reading the essays might help explain the gap, a few participants' comments suggested that where difficulties were perceived, efforts were made to cope with them. This might also help explain why perceived difficulties did not always translate into observed weaknesses. For example, one of the most successful writers of the group, Monica, reported having difficulty with the structure of the essay. Monica reported spending 30 hours on the assignment, writing seven drafts, and using several types of strategies, including asking for clarifications of the assignment, asking for a sample, mental planning, looking for models, seeking feedback, and constantly monitoring her writing. The end product was a wellstructured essay even though this was the first essay Monica ever wrote in English, and she reported experiencing a tremendous amount of difficulty and pressure while working on the assignment. At the beginning of the essay, Monica provided relevant background, introduced her topic (multilevel classroom), and presented her position. She then went on to define the term multilevel classroom and analyze why these classrooms existed and why some people supported these classrooms. Finally, she defended her position-why she believed these classrooms were ineffective.

\section{Question 2. What processes and strategies do L2 writers use when they} perform an argumentative writing task in English?

Participants' oral reports on writing processes covered topic selection, planning, and revising. The overwhelming majority (11) selected topics specifically related to their job-language teaching. Usefulness or relevance of the topic to their job and familiarity with the topic were two main reasons given by the participants for topic selection. For example, Felipe said that he chose his topic (teaching ESL in Mexico) "because I am interested in that topic. I am working there. I can relate some experience and I can, I know something about it so I want to take advantage of it" (Felipe's transcript, p. 3). The tendency to select a familiar topic suggested that through writing the essay, participants tried to achieve both professional and personal goals-reflecting 
on or learning more about second-language teaching. Also, it indicated that in the face of a largely unfamiliar task, the participants tried to capitalize on what they were already familiar with to cope with the other demands of the task. Four participants also reported doing research to narrow down the topic or to gather more information.

As for planning, six participants reported that they did not engage in any kind of activities to generate content or plan before writing; they "just wrote." Three reported brainstorming before writing, and four said they took notes on what they wanted to write before starting to write. Four said they used outlines, and one said she "mentally planned" before writing. Several participants said they used more than one activity to prepare for writing.

As for revision, most participants said that they wrote drafts. Six said they wrote one draft; two said they wrote two drafts; two others said they wrote three to four drafts; and one participant, Monica, said she wrote seven drafts. Three said that they did not write any separate drafts, and they "revised directly (on the computer) and doing all the corrections" (Pedro's transcript, p. 8). Participants reported working on content, organization, and style during revision. Interestingly, for many of the participants, revision meant cutting what had already been written to be more concise. For example, Sonia said that revision meant "cutting the words without cutting the ideas" (Sonia's transcript, p. 5). For editing, participants were more concerned with vocabulary than with grammar; for some, editing was done "in the sense that we try the most precise words" (Martha's transcript, p. 6). Participants said that much time was spent on choosing appropriate words.

Participants reported using a variety of strategies, and those reported by at least two participants are summarized in Table 2. As shown in the table, asking for feedback on the draft(s) was mentioned by 11 participants. Participants indicated that they sought feedback from various sources, including the instructor, their classmates, and a native speaker who volunteered to help the group. One participant, Pedro, described how he elicited feedback from his peers:

I gave it to a couple of classmates in the group, and I was asking them, you know, "do you think this is understandable?" "Does this represent what I am trying to say?" What I did was asking them to read it and tell me what you [they] understand from this to see if that matches what I am trying to say. (Pedro's transcript, p. 9)

However, participants differed with respect to their perception of the value of peer feedback, although most agreed that it was helpful. For example, Gabriela said that she asked for peer feedback and found the feedback useful. When the peer told her that she did not stay on topic, she revised her essay accordingly. Teresa, however, said that she did not use peer feedback because the suggested changes would entail a different way of expressing 
Table 2

Strategies Reported by the Participants $(N=14$

$\begin{array}{lr}\text { Ask for feedback on draft(s) } & 11 \\ \text { Use models } & 5 \\ \text { Talk to peers and native speaker helper } & 4 \\ \text { Ask to see peer writing } & 2 \\ \text { Use knowledge about English writing from previous course(s) } & 2\end{array}$

herself and an overhaul of the whole structure, which she was not sure would be necessary. The somewhat conflicting opinions on peer feedback perhaps reflected lack of experience on the part of some participants in giving and receiving peer feedback.

Another strategy reported by the participants was using models, in this case handbooks on writing and writing examples. Although asking for feedback seemed to be a general strategy that allowed the writer to get feedback on different aspects of writing, using models was reported to address specifically the perceived difficulty with organization. Those who checked models generally found them helpful. One participant, Mario, said that he "went to the library to look for information about how to write argumentative essay ... and tried to follow the examples" (Mario's transcript, p. 2). Other strategies participants reported included talking to peers and the native speaker volunteer to find a topic or to get information about argumentative writing, ${ }^{5}$ asking to see peer writing, and applying what they had already learned about English writing. Two participants had taken English courses in the US and said that they followed what their English teachers had taught them. For example, in reference to conclusion, Mario said,

I tried to remember what my teachers tell me. One of the things I remember that my English teachers said was that when you conclude, you have to talk about the most important information that you include in the body, using different words, (Mario's transcript, p. 5)

This was exactly what Mario did, as shown in his conclusion cited above.

Participants perceived performing the argumentative writing task as a learning experience through which they learned about their own writing abilities as well as about different aspects of English argumentative writing (e.g., to organize ideas, to be direct, to support their position, to acknowledge arguments from the opposition). Although it is beyond the scope of this article to address participants' learning in depth, it would be a remiss if I did not mention that from the participants' perspective, learning did not always lead to personal satisfaction. For example, five participants said that they learned about the important parts of the argumentative essay and about how 
to sequence ideas. Three of the five, however, indicated that although they learned to produce better structured argumentative essays in English as judged by external criteria, they did not like their essays because they felt detached from their own writing. For example, Monica said that she did not like her essay because it was not written in her style. Sonia felt the same because, "when you have to read it, some parts sound like it's not from you" (Sonia's transcript, p. 6).

\section{Discussion and Conclusion}

This study examined the difficulties and writing processes and strategies of a group of Mexican graduate students working on an argumentative writing assignment in English. Results of data analysis indicate that from the participants' perspective, rhetorical concerns (e.g., organization and development of arguments) were a major challenge, although without a doubt the linguistic aspects (e.g., vocabulary) also posed problems. Results also indicate that the participants used a variety of strategies. Care needs to be taken, however, when interpreting the results, because the number of participants in this study was relatively small, and the group was homogeneous (ESL teachers from the same language background). The results nevertheless provide some insights into the difficulties, processes, and strategies of secondlanguage writers learning to do English argumentative writing.

Results of the study suggest the lack of rhetorical knowledge and skill as a major cause of difficulty for ESL writers with limited writing experience when they perform an argumentative writing task. Participants' comments concerning their rhetorical difficulties are compatible with some of the results of text-based studies on L2 English argumentative writing. In this study, the participants perceived organization and development of arguments as the major areas of difficulties, and these were among the most challenging areas identified in Al-Abed-Al-Haq and Ahmed's (1994) study examining argumentative writing by Arabic ESL writers. These results suggest that organization and development of arguments can be challenging to ESL/EFL students from different backgrounds, and not only from the textual perspective, but also from the learners' own points of view. Also, some participants' comments concerning preferring an elaborate style in Spanish writing were congruent with observations made in Lux's (1991) study. Further, participants' comments indicate that from the learners' perspective several factors, including cultural and linguistic background, L1 writing ability, and experience with academic writing in L1 and L2, could help explain the rhetorical difficulties they experienced. These comments thus support the argument that factors other than the writers' cultural and language backgrounds can influence the rhetorical features in L2 writing (Connor, 1996; Matsuda, 1997). An implication of this result for L2 writing instruction is that writing teachers cannot assume that L2 writers from the 
same cultural and language background will have the same difficulties for the same reasons.

Results of this study also reveal the value of eliciting learners' input in assessing difficulties. In the present study, the reported difficulties did not always match weaknesses observed in the final products. However, that the written texts did not exhibit major weaknesses with respect to certain aspects of writing does not mean that the writers did not experience major difficulties with these aspects in the writing process. Some of the difficulties might not be reflected in the written products because they have been dealt with during the process. Also, because the difficulties encountered by ESL writers relate not only to textual features of writing, but also to the writing process (e.g., selecting the topic) and pertain to the cognitive as well as affective domains, as indicated by participants' comments, it may not be advisable to rely on text analysis alone when we try to understand learners' difficulties. Reading participants' essays did not always tell me the difficulties and pressure participants in this study experienced. Combining text analysis with direct learner input seems to be optimal if we wish to understand the full range of learners' difficulties and needs.

The findings on writing processes and strategies indicate that the participants in this study were resourceful learners. In the face of a new and challenging task, they employed various types of strategies without explicit instruction on writing strategies. Many of the participants were able to select several strategies to address their difficulties, suggesting that these participants played an active role in the writing process. The strategies reported by the participants such as asking for feedback, looking for models, and using past ESL writing training were similar to those discussed in Leki's (1995) study, which examined the strategies used by ESL students to cope with academic writing in content courses. Results of the study also suggest that L2 writers such as those in the study, however, may not automatically be able to select a full range of strategies. Classifying the participants' strategies using the framework proposed by Riazi (1997) reveals that most of the strategies participants reported fell into three of the four categories: cognitive, social, and search. Metacognitive strategies, however, were largely not mentioned by the participants, even though these strategies are "directly responsible for the execution of a writing task" (Wenden, 1991, p. 315). Although the participants found the structure/organization of English argumentative writing difficult, only five engaged in planning activities in which both the content and organization were considered (e.g., through outlines and mental planning). Only one person, Monica, specifically mentioned that she monitored her writing process by continually asking what she wanted to say and checking to see whether she had said it. The lack of metacognitive strategies reported in this study perhaps could be explained 
partly by the limited academic writing experience of some of the participants.

Although it is premature to offer suggestions for teaching based on findings from a small group of participants, results of the study do have potential implications for L2 writing instruction. First, findings concerning students' difficulties indicate a need for rhetorical knowledge. Although second-language learners are still developing language skills, lack of language skills does not necessarily present the greatest challenge in L2 argumentative writing from the L2 writers' point of view. Thus an important responsibility of L2 writing teachers is to help students develop rhetorical knowledge in L2. Care must be taken, however, in presenting rhetorical knowledge to students. Because writers may experience difficulty with the rhetorical aspects of English argumentative writing for different reasons, and because how one writes can be seen as a reflection of one's cultural and/or personal identity as some participants in this study indicated, teachers should not impose a particular form, but should rather help students understand why certain choices are made.

Second, findings of the study suggest that helping students develop metacognitive strategies perhaps should have a special place in second-language writing strategy training because these strategies may not be used automatically by L2 writers. Metacognitive strategy training may be particularly beneficial for writers who have limited writing experience even in their first language, like some of the participants in this study. Teachers can model metacognitive strategies, promote in students an awareness of these strategies, and help them reflect on their use of various strategies. Also, L2 writing instructors may wish to consider addressing affective strategies in strategy training. Asking students to reflect on how they deal with affective difficulties associated with writing and to share their experiences with peers can help L2 learners build a repertoire of affective strategies.

Third, in order to understand better and respond to students' difficulties, L2 writing teachers may wish to ask students frequently what difficulties they have and what help they feel they need and to consider students' input when designing instructional activities. The writing conference would be a perfect place for teachers to ask students about their difficulties, although too often discussions during the writing conferences center on what students have written (i.e., product-based). Although I met with some of the participants to discuss their drafts in writing conferences, it was not until I interviewed them that I realized what they went through. Therefore, I would like to suggest that more discussion in writing conferences be directed to discussing the difficulties, strategies, and processes involved in producing students' texts. It is important that we gain a sense of how the text is evolving and provide timely support and instruction. 
Learning to do argumentative writing in a second language is a challenging task. An understanding of learners' difficulties and processes allows teachers to provide relevant instruction. Future research can assist this endeavor by examining learners' needs further and by investigating other questions. For example, what is the relationship between perceived difficulties, strategy use, and rhetorical and syntactic features in written products? What factors affect learner perception and assessment of their own difficulties? Such research could provide considerable insight into L2 writing processes and inform L2 writing instruction.

\section{Notes}

${ }^{1}$ There were 18 students in the group. All were willing to participate in the study, but due to time constraints, I was able to interview only 14 of them.

${ }^{2}$ In addition to the argumentative essay, all students in the course were required to write a paper about their language-learning experience (first- or second-language-learning experience). The participants in the study also completed a research paper in small groups.

${ }^{3}$ Formal peer or teacher-student conferences were not scheduled in class for this assignment due to limited class time. I scheduled a special session with the Mexican students outside of class to answer their questions and to go over issues concerning academic format and documentation.

${ }^{4}$ Several participants used the term format to refer to the structure or organization. For example, Teresa defined format of English writing as "this English style on writing, what you have to present is like an introduction and then giving details of that information. So you might start like with a general topic, and then give details" (Teresa's transcript p. 11).

${ }^{5}$ Several participants said that the native speaker they worked with provided useful information about English argumentative writing.

\section{Acknowledgments}

I would like to thank all 18 Mexican graduate students with whom I worked during the summer of 1998. This research would not have been possible without their enthusiasm and help. I would also like to thank Ruth Roux-Rodriguez, the editors of TCI, and two anonymous reviewers for their invaluable comments on earlier versions of this article.

This article is a revised version of a paper I presented at the 1999 Southeast Regional TESOL Conference, November 4-6, Birmingham, Alabama.

\section{The Author}

Wei Zhu is an assistant professor at the University of South Florida at Tampa. She has worked with ESL students in China and the United States. Her research interests include peer response, academic literacy, and writing strategies. Her work has appeared in Written Communication and Language Learning.

\section{References}

Al-Abed-Al-Haq, F., \& Ahmed, A.S.E.A. (1994). Discourse problems in argumentative writing. World Englishes, 13, 307-323.

Bouchard, R. (1996). Argumentative competence and written production in foreign and native languages. Langue-Francaise, 112, 88-105.

Choi, Y.H. (1986). A study of coherence in Korean speakers' argumentative writing in English. Studies in the Linguistics Sciences, 16, 67-94 
Choi, Y.H. (1988a). Text structure of Korean speakers' argumentative essays in English. World Englishes, 7, 129-142.

Choi, Y.H. (1988b). Textual coherence in English and Korean: An analysis of argumentative writing by American and Korean students. Dissertation Abstracts International, 50(2), 429-A.

Connor, U. (1996). Contrastive rhetoric: Cross cultural aspects of second language writing. Cambridge, UK: Cambridge University Press.

Cumming, A. (1989). Writing expertise and second language proficiency. Language Learning, $39,81-141$.

Ferris, D. (1994). Rhetorical strategies in student persuasive writing: Differences between native and non-native English speakers. Research in the Teaching of English, 28, 45-65.

Hall, C. (1990). Managing the complexity of revising across languages. TESOL Quarterly, 24, 43-60.

Hinkel, E. (1999). Objectivity and credibility in L1 and L2 academic writing. In E Hinkel (Ed.), Culture in second language teaching and learning (pp. 90-108). Cambridge, UK: Cambridge University Press.

Khaldieh, S. (2000). Learning strategies and writing processes of proficient vs. less-proficient learners of Arabic. Foreign Language Annals, 33, 522-534.

Kim, J.W. (1996). Linguistics, rhetorical, and strategic aspects of Korean students' persuasive writing in English. Dissertation Abstracts International, 57(2), 609-A.

Matsuda, P.K. (1997). Contrastive rhetoric in context: A dynamic model of L 2 writing. Journal of Second Language Writing, 6(1), 45-60.

Leki, I. (1995). Coping strategies of ESL students in writing tasks across the curriculum. TESOL Quarterly, 29, 235-260.

Leki, I., \& Carson, J. (1994). Students' perceptions of EAP writing instruction and writing needs across the disciplines. TESOL Quarterly, 28, 81-101.

Lux, P. (1991). Discourse styles of Anglo and Latin American college students writers. Dissertation Abstracts International, 52, 06A, 2128.

Raimes, A. (1987). Language proficiency, writing ability, and composing strategies: A study of ESL college student writers. Language Learning, 37, 439-467.

Reinking, J., Hart, A., \& Osten, R. (1993). Strategies for successful writing. Englewood Cliffs, NJ: Prentice-Hall.

Riazi, A. (1997). Acquiring disciplinary literacy: A social-cognitive analysis of text production and learning among Iranian graduate students of education. Journal of Second Language Writing, 6, 105-137.

Seliger, H., \& Shohamy, E. (1989). Second language research methods. New York: Oxford University Press.

Wallace, M. (1998). Action research for language teachers. Cambridge and New York: Cambridge University Press.

Wenden, A. (1991). Metacognitive strategies in L2 writing: A case for task knowledge. In A. James (Ed.), Georgetoton university round table on languages and linguistics (pp. 303-322). Washington, DC: Georgetown University Press.

Whalen, K., \& Menard, N. (1995). L1 and L2 writers' strategic and linguistic knowledge: A model of multiple-level discourse processing. Language Learning, 45, 381-418.

\section{Appendix \\ Interview Protocol}

The individual interviews elicited information in two major areas: participants' backgrounds and their experiences writing the argumentative essay. Each interview consisted of 45 predetermined questions. Thirty questions concerned the participants' backgrounds and were mostly closed- 
ended (participants could choose from predetermined categories such as very well, well, fairly well, not well) or required short responses. The other 15 questions pertained to participants' experiences with the argumentative assignment and were largely open-ended. My role during the interviews was primarily to ask questions, clarify the questions when necessary by rephrasing or giving examples, prompt the participants for response, and frequently check for confirmation of my own understanding of participants' responses.

I first gathered information concerning participants' backgrounds. Some of the questions asked during this part of the interview included

- What is your TOEFL score?

- When did you start to learn English?

- What degrees have you obtained?

- How long have you been teaching English?

- Have you attended a college/ university in an English-speaking country? If so, where and for how long?

- How well do you write in Spanish?

- Is this the first time you have written an essay in English?

Then I elicited information about participants' experiences with the argumentative essay. Some of the questions asked included

- How did you write this paper? Describe the writing process of this paper.

- How many drafts did you write?

- Was this essay easy/difficult for you to write? What were the difficulties you encountered when writing this essay?

- What did you do to overcome the difficulties?

- What did you learn from this assignment about English argumentative writing? 